\title{
IMPROVING FAMILY AND COMMUNITY HEALTH IN EASTERN EUROPE - THE LIFECYCLE APPROACH AT WHO
}

\author{
Jeffrey V. Lazarus ${ }^{1,2}$, Christina Bjørk ${ }^{3}$, Mikael Østergren ${ }^{4}$ \\ ${ }^{1}$ STI/HIVIAIDS Programme, World Health Organization, Regional Office for Europe, Copenhagen, Denmark \\ ${ }^{2}$ Division of Social Medicine and Global Health, Lund University, Sweden \\ ${ }^{3}$ Department of Health Sciences, Copenhagen University, Denmark \\ ${ }^{4}$ Child and Adolescent Health and Development, World Health Organization, Regional Office for Europe, Copenhagen, Denmark
}

\begin{abstract}
SUMMARY
There are great differences in the health status of young children in the European Region. Central Asia and the Caucasus are the worst-off areas. After reviewing under-five mortality in the eight countries of this part of Eastern Europe, a new WHO strategy to improve child survival is presented. Adopted in late 2005, the strategy has four main principles: a lifecycle approach, youth participation, equity and intersectoral collaboration.
\end{abstract}

Key words: health status, children, Eastern Europe, community health

Address for correspondence:

Jeffrey V. Lazarus, STI/HIV/AIDS Programme, World Health Organization Regional Office for Europe, Scherfigsvej 8, DK-2100 Copenhagen $\varnothing$, Denmark. E-mail: jla@euro.who.int

\section{INTRODUCTION}

Babies are to be born as healthy as possible and progress through childhood and adolescence with a minimum of disruption, difficulty and disability. However, this is not uniformly the case in the 52 countries of the WHO European Region (Fig. 1). A new report by WHO (1) concludes that even in Europe most low-income countries will not meet the Millennium Development Goals, agreed on in 2000 by 189 countries, if the trends from the 1990s continue. Data have shown that countries with high child mortality have not improved their situations and death rates have even worsened in some (2).

We reviewed mortality and morbidity data for the five central Asian republics (Kazakhstan Kyrgyzstan, Tajikistan, Turkmenistan and Uzbekistan) and the three Caucasus countries (Armenia, Azerbaijan and Georgia). All eight countries are part of the former Soviet Union and as such underwent an abrupt change in the organization of their health systems and a concurrent decline in the population's health status (3), as measured by inter alia life expectancy, cardiovascular disease and sexually transmitted infections (4). Here, in addition to reviewing the health status of children under the age of five in these countries, we also look at innovative changes in how the WHO Regional Office for Europe is addressing these problems.

\section{CHILD HEALTH IN CENTRAL ASIA AND THE CAUCASUS}

Although under-5 mortality is declining in the European Region, the probability of dying before the age of five continues to be of particular concern in the central Asian republics (CAR), other countries of the Commonwealth of Independent States and some countries of southern Europe (5). According to WHO estimates (3), the under- 5 mortality varies by a factor of 40 between the countries with the lowest and the highest mortality in Europe. Data from the eight countries in CAR and the Caucasus show that they have higher under-five and neonatal mortality than the European Region on average. The rates WHO estimated in Table 1 show that Tajikistan and Turkmenistan stand out with an extremely high estimated under-5 mortality of 118 and 102 deaths per 1000 live births, respectively, and neonatal mortality rates of 38 and 35 per 1000 live births, respectively. The latter are closely followed by Kazakhstan and Kyrgyzstan. Azerbaijan and Georgia lead the Caucasus with regards to neonatal mortality, both at 25 per 1000 , and under-5 mortality at 91 and 45 per 1000 live births. The rates far exceed the European average of 11/1000. These figures clearly demonstrate the need for urgent interventions that improve child survival as well as child health and development $(6,7)$.

\section{A REGIONAL STRATEGY FOR PRIORITISING CHILD HEALTH}

Inequity in health needs to be reduced, but prioritising among several key areas is difficult and may often be resource demanding. Reaching the Millennium Development Goal for child survival will require the delivery of sustainable interventions and strategies to a high proportion of children and mothers (8, $9)$. Increased vaccination coverage (10), access to antenatal care (11) and environmental improvements (12) are some of the main needed interventions; however, local ownership including 


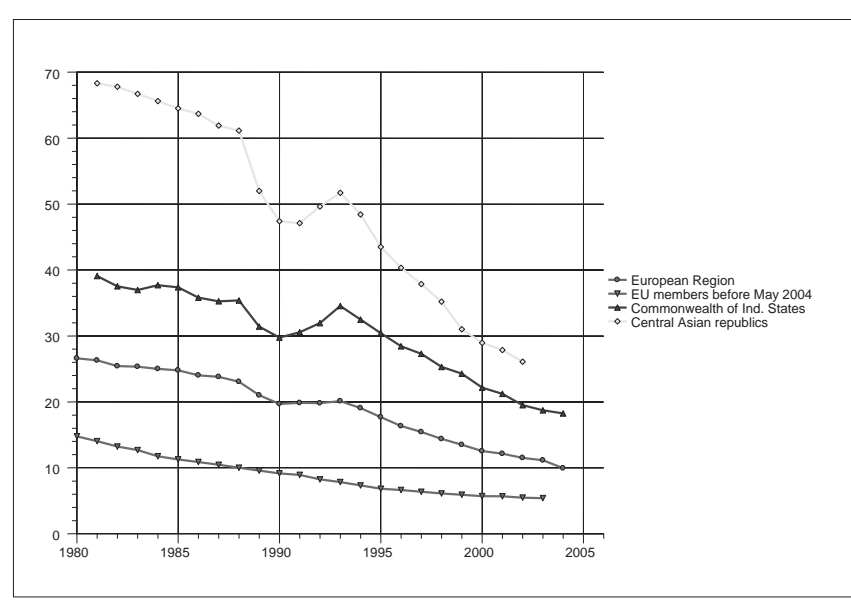

Source: WHO Regional Office for Europe health for all database, www.euro.who. int/hfadb (accessed 24 July 2006).

Fig. 1. Probability of dying before the age of 5 per 1000 live births in three selected groups of countries in Europe - EU countries before May 2004, Central Asian republics and the Commonwealth of Independent States (CIS).

selecting the interventions and strategies and adapting them to social, economic and cultural contexts can be both complicated and time consuming. To assist member states, the WHO Regional Office for Europe has recently developed a regional strategy on child and adolescent health (13) that focuses on seven priority areas within child and adolescent health (Table 2). The strategy was developed in collaboration with member states, and was presented and approved at the WHO Regional Committee's fifty-fifth session in September 2005. Because of large cultural, social, economic and demographic differences in the Region, the strategy is to be seen as a guiding set of tools, and not a detailed blueprint, to help countries to prioritise and implement actions to improve child and adolescent health.

\section{A LIFECYCLE APPROACH AT WHO}

The regional strategy is based on an integrated approach developed by the Family and Community Health unit of the WHO Regional Office for Europe. It is clear that each stage of development involves determinants of health, biological risk and life events that will interact with each other. This interrelation will last throughout life and will even continue to future generations. Therefore, family and community health should be seen as an integrated task that deals with child and adolescent health in a circular, holistic way to ensure the health of the individual throughout the life course.

To ensure the continuity and avoid overlap, WHO/Europe has applied the lifecycle approach in the organization of its programmes and to the new regional strategy (Fig. 2). The idea of family and community health as a circular and holistic process is far from new and can be described by the lifecycle approach, which illustrates the main environmental and socio-cultural challenges for each stage of childhood and adolescence (14). Despite the benefits of integrated and horizontal efforts, few organizations employ this approach. The WHO lifecycle approach addresses
Table 1. The estimated under-five and neonatal mortality rates in eight countries in Europe

\begin{tabular}{|c|c|c|}
\hline & $\begin{array}{l}\text { Estimated pro- } \\
\text { bability of dying } \\
\text { before age } 5 \\
\text { (per } 1000 \text { live } \\
\text { births) }{ }^{a}\end{array}$ & 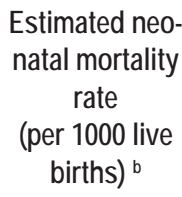 \\
\hline Armenia & 33 & 17 \\
\hline Azerbaijan & 91 & 25 \\
\hline Georgia & 45 & 25 \\
\hline Kazakhstan & 73 & 32 \\
\hline Kyrgyzstan & 68 & 31 \\
\hline Tajikistan & 118 & 38 \\
\hline Turkmenistan & 102 & 35 \\
\hline Uzbekistan & 69 & 27 \\
\hline WHO European Region average & 11 & 4 \\
\hline EU before May 2004 average & 6 & 3 \\
\hline
\end{tabular}

Sources: a) World Health Report 2005. These figures are computed by WHO to ensure comparability; they are not necessarily official statistics of Member States, which may use alternative methods. b) WHO Regional Office for Europe, European health for all database, www.euro.who.int/hfadb (accessed 14 July2005).

key aspects of child and adolescent health, reproductive health, maternal health and gender mainstreaming in an integrated section, called family and community health, to achieve a more favourable outcome through collaboration and co-ordination. Two of the priority areas in the new strategy relate to specific stages in the life-course, namely maternal and newborn health, and adolescent health. Maternal and neonatal health will of course have an impact on the future well being of the developing child. Similarly, adolescent health and development will lay the foundations for health in later life and contribute to the health status of the next generation. The remaining five priority areas for WHO act as cross-cutting themes, influencing health and development at all stages of the lifecycle.

\section{CO-OPERATION AND LINKED PROGRAMMES}

The first sign of integrating approaches within child and adolescent health was the development of a Global Strategy on the Integrated Management of Childhood Illness (15). The programme integrates basic care for the most common childhood illnesses, preventive measures and family and community practices. Additionally, reproductive health has been linked to family and community health, and on 17 May 2004, WHO approved a global reproductive health strategy to "accelerate progress towards the attainment of international development goals and targets". Grounded in the Millennium Development Goals, the WHO strategy focuses on meeting the three goals specifically 


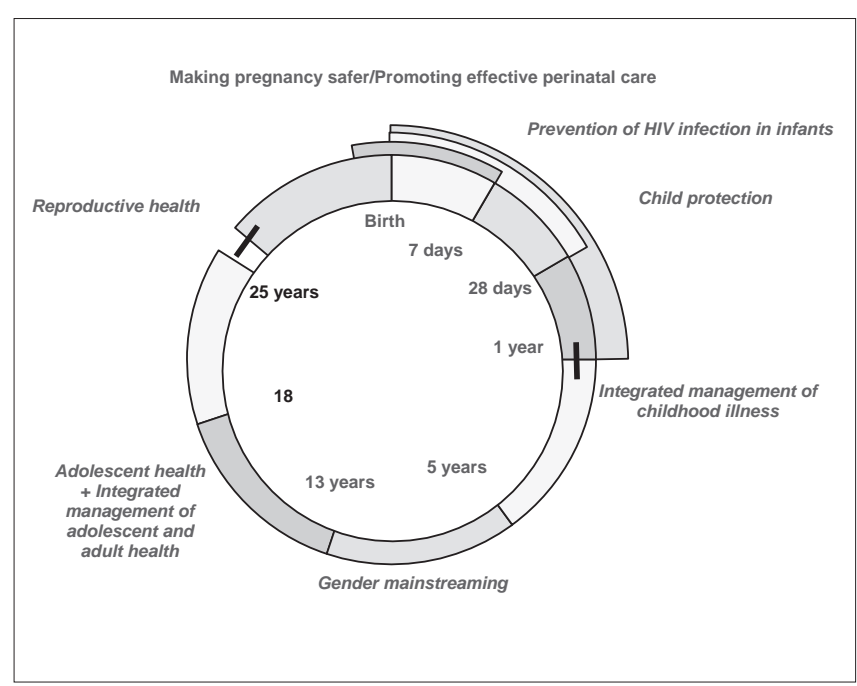

Fig. 2. The lifecycle approach.

related to reproductive health: improving maternal health, reducing child mortality and combating HIV/AIDS, malaria and other infectious diseases. The targets set in these goals are to reduce 1990 levels by three-quarters by 2015 (16). The strategy further clarifies why reproductive health is unique as compared to other fields of health and why it needs to be an integrated part of family and community health. It states, "Reproductive health extends before and beyond the years of reproduction, and is closely associated with socio-cultural factors, gender roles and the respect and protection of human rights ...".

The Making Pregnancy Safer programme, launched in 2000, co-operates closely with the reproductive health programme and the programme on child and adolescent health and development at $\mathrm{WHO}$ /Europe. However, to improve the health situation it is not sufficient to just integrate the programmes at WHO. The health systems in low-income countries need to be developed to improve linkages between the aforementioned programmes of work. In effect, all aspects of maternal and child health should be interlinked within the context of policy and health systems support, appropriate case management, good family

Table 2. The priority areas for Child and Adolescent Health and Development

\begin{tabular}{|c|l|}
\hline \multicolumn{2}{|c|}{$\begin{array}{r}\text { WHO's seven priorities for Child and Adolescent } \\
\text { Health and Development }\end{array}$} \\
\hline 1. & Maternal and neonatal health \\
\hline 2. & Nutrition \\
\hline 3. & Communicable diseases \\
\hline 4. & Physical environment \\
\hline 5. & Adolescent health \\
\hline 6. & Injuries and violence \\
\hline 7. & The physical environment \\
\hline
\end{tabular}

Source: WHO Regional Office for Europe. Strategy for Child and Adolescent Health and Development. Copenhagen, WHO Regional Office for Europe, 2005 and community practices and the implementation of the United Nations Convention on the Rights of the Child.

\section{CONCLUSION}

Despite improvement in child health in Europe, we have found great inequity in child survival and health. Eight countries of the former Soviet Union have shown greater numbers of under-5 and neonatal mortality than the rest of Europe. In order to reach the Millennium Development Goals, immediate improvements are needed and therefore $\mathrm{WHO}$ /Europe has developed a regional strategy to support the countries in prioritising and decision-making. The new lifecycle approach at WHO illustrates that the health of the child and adolescent is intimately linked and shows that prevention and health promotion in one generation will benefit the health, well-being and productivity of the next generation. Furthermore, the lifecycle approach can help programmes identify where they have linkages with each other, whether they are targeting, partially or fully, the same group, and motivate for further horizontal collaboration. Eventually, co-ordinating and co-operating programmes and interventions will likely result in long-term improvements in child and adolescent health and development and thus be beneficial to economic growth and sustained improvements in public health.

\section{REFERENCES}

1. World Health Organization. Health and the Millennium Development Goals. Geneva: World Health Organization; 2005.

2. The European Health Report: 2005: public health action for healthier children and populations. Copenhagen: WHO Regional Office for Europe; 2005.

3. McKee M, Healy J, Falkingham J, editors. Health Care in Central Asia. Buckingham: Open University Press; 2002.

4. World Health Organization, Regional Office for Europe. European health for all database [database on the Internet]. Copenhagen: WHO Regional Office for Europe; c2005 [cited 2005 Nov 7]. Available from: http://www. euro.who.int/hfadb.

5. The World Health Report: 2005: make every mother and child count. Geneva: World Health Organization; 2005.

6. Black RE, Morris SS, Bryce J. Where and why are 10 million children dying every year? Lancet. 2003 Jun 28;361(9376):2226-34

7. Victora CG, Wagstaff A, Schellenberg JA, Gwatkin D, Claeson M, Habicht JP. Applying an equity lens to child health and mortality: more of the same is enough. Lancet. 2003 Jul 19;362(9379):233-41.

8. Bryce J, el Arifeen S, Paiyo G, Lanata C, Gwatkin D, Habicht JP; MultiCountry Evaluation of IMCI Study Group. Reducing child mortality: can public health deliver? Lancet. 2003 Jul 12;362(9378):159-64.

9. Wagstaff A, Claeson M. The Millennium Development Goals for health: Rising to the Challenges. Washington, DC: World Bank; 2004.

10. World Health Organization, Regional Office for Europe. Vaccine-preventable Diseases and Immunization programme - Programme report and future Initiatives 2001-2005. Copenhagen: WHO Regional Office for Europe; 2005.

11. Darmstadt GL, Bhutta ZA, Cousens S, Adam T, Walker N, de Bernis L; Lancet Neonatal Survival Steering Team. Evidence-based, cost-effective interventions: how many newborn babies can we save? Lancet. Mar 1218;365(9463):977-88.

12. Valent F, Little D, Bertollini R, Nemer L, Barbone F, Tamburlini G. Burden of disease attributable to selected environmental factors and injury among children and adolescents in Europe. Lancet. 2004 Jun 19;363(9426): 2032-9. 
13. World Health Organization, Regional Office for Europe. European strategy for child and adolescent health and development. Copenhagen: WHO Regional Office for Europe; 2005.

14. Kudlová E. Life cycle approach to child and adolescent health. Cent Eur J Publ Health. 2004;12(3):166-70.

15. World Health Organization, Division of Child Health and Development. Improving Child Health. IMCI: the integrated approach. Geneva: World Health Organization; 1997.
16. United Nations [homepage on the Internet]. UN Millennium Development Goals [cited 2005 Jul 8]. Available from: http://www.un.org/ millenniumgoals/

Received January 9, 2006 Received in revised form and accepted March 17, 2006 